\title{
Comparison of electrocardiographic and echocardiographic measures of left ventricular hypertrophy in the assessment of aortic stenosis
}

\author{
MARK DANCY \\ From the Department of Cardiology, St George's Hospital, London
}

SUMMARY One hundred and nineteen patients with a clinical diagnosis of important aortic stenosis were assessed clinically and by electrocardiography and $M$ mode echocardiography to determine the degree of left ventricular hypertrophy. Predicted left ventricular pressure was calculated from two previously described formulas. Comparisons were made between the various methods for assessing left ventricular hypertrophy to see which method most reliably predicted the severity of the stenosis as defined by invasive measurement of left ventricular pressure and peak aortic valve gradient. Direct measurement of left ventricular wall thickness from the echocardiogram, expressed as the mean of septal and posterior wall thickness, was the most accurate predictor ( $r=0.75$ for 29 patients with high quality echocardiograms), and surpassed derived indices (left ventricular mass $(r=0.68)$ and predicted left ventricular pressure derived from the two formulas $(r=0.39$ and $r=0.68)$ ) in adults. Echocardiographic results were significantly better than electrocardiographic, but only when the recordings were of very high quality. Average quality echocardiograms were no better than precordial electrocardiographic voltages for predicting the severity of aortic stenosis. The formulas for predicting left ventricular pressure were of more value in children than in adults, but they were still not sufficiently accurate to be predictive in individual cases. Electrocardiographic voltages were more accurate predictors of the severity of aortic stenosis in children than in adults.

The detection of left ventricular hypertrophy has become an important clinical goal, particularly for the diagnosis of aortic valve disease and the assessment of hypertension. There are several methods of evaluating left ventricular hypertrophy - palpation of the apex beat, measurement of numerous electrocardiographic variables, and, more recently, echocardiography-but there is little information about the relative reliability of these various techniques in predicting the severity of aortic stenosis.

This study compares the clinical, electrocardiographic, and echocardiographic assessments of left ventricular hypertrophy with the haemodynamic findings in patients suspected of having important aortic stenosis.

Requests for reprints to Dr Mark Dancy, Department of Cardiology, St George's Hospital, London SW17 0QT.

Accepted for publication 6 August 1985

\section{Patients and methods}

One hundred and nineteen patients with a clinical diagnosis of important aortic stenosis were studied at admission for cardiac catheterisation. There were 71 males and 48 females (mean age of 51 years, range 16-76). All patients had undergone clinical assessment, 12 lead electrocardiogram, and $M$ mode echocardiography in addition to cardiac catheterisation. Mean peak systolic gradient across the aortic valve was 68 (35) $\mathrm{mm} \mathrm{Hg}$, and mean left ventricular pressure was 197 (41) mm Hg. Patients with bundle branch block, previous myocardial infarction, established hypertension, or important aortic valve regurgitation were excluded.

The presence or absence of left ventricular hypertrophy was assessed clinically by palpation of the cardiac apex with the patient turned on the left side. Two measures of precordial electrocardiographic voltage were used: the Sokolow-Lyon 
index $^{1}(\mathrm{~S}-\mathrm{V} 1+\mathrm{R}-\mathrm{V} 5$ or $\mathrm{V} 6 \geqslant 35 \mathrm{mV})$ and the McPhie index ${ }^{2}(\max S+\max R \geqslant 45 \mathrm{mV})$. The presence or absence of appreciable lateral ST depression ( $>1 \mathrm{~mm}$ ) was noted. No patient was taking digoxin. Standard $M$ mode echocardiograms were measured with a Numonics analyser (Smith Kline instruments) that allows rapid repeated measurements of the same variable in different cardiac cycles and produces a mean value. At least five measurements were made for each variable. The following were measured by the method recommended by the American Society of Echocardiography $^{3}$ : interventricular septal thickness at end systole and end diastole (IVS and $_{\mathrm{IVS}}$ ); posterior free wall thickness of the left ventricle at end systole and end diastole $\left(\mathrm{LVW}_{\mathrm{s}}\right.$ and $\mathrm{LVW}_{\mathrm{d}}$ ); and left ventricular minor axis dimension at end systole and end diastole $\left(D_{s}\right.$ and $\left.D_{d}\right)$. From these data the following were calculated:

(a) Mean left ventricular wall thickness at end systole and end diastole ( mean $_{\mathrm{s}}$ and mean $_{\mathrm{d}}$ ) by dividing the sum of septal and posterior wall thicknesses by two.

(b) Diastolic left ventricular mass by the Teichholz formula ${ }^{4}$ to derive left ventricular volume (taking the specific gravity of cardiac muscle to be $1.05 \mathrm{~g} / \mathrm{cm}^{3}$.

$$
\begin{aligned}
& \operatorname{Mass}(\mathrm{g})=1.05\left(\left(\frac{7}{\mathrm{LVW}_{\mathrm{d}}+\mathrm{IVS}_{\mathrm{d}}+\mathrm{D}_{\mathrm{d}}+2 \cdot 4}\right) \times\right. \\
&\left.\left(\mathrm{LVW}_{\mathrm{d}}+\mathrm{IVS}_{\mathrm{d}}+\mathrm{D}_{\mathrm{d}}\right)^{3}-\left(\frac{7}{\mathrm{D}_{\mathrm{d}}+2 \cdot 4}\right) \times \mathrm{D}_{\mathrm{d}}{ }^{3}\right)
\end{aligned}
$$

(c) Predicted left ventricular pressure $\left(\mathrm{LVP}_{\mathrm{p}}\right)$ by two formulas:

$$
\mathrm{LVP}_{\mathrm{p}}=225 \times\left(\mathrm{LVW}_{\mathrm{s}} / \mathrm{D}_{\mathrm{s}}\right) \mathrm{mm} \mathrm{Hg}^{6}
$$

and

$$
\mathrm{LVP}_{\mathrm{p}}=6+298 \times \text { mean }_{\mathrm{d}} / \mathrm{r} \mathrm{mm} \mathrm{Hg}^{7}
$$

where $r=$ is the diastolic cavity radius.

(d) Mean rate of circumferential shortening (mean Vcf) was calculated in circumferences per second as a measure of overall left ventricular function from the formula described by Fortuin et al. ${ }^{8}$

Patients with reduced left ventricular function (mean Vcf $<1 \mathrm{circ} / \mathrm{s}$ ) were excluded from parts of the analysis as it had been stressed in a previous study that the assumptions necessary for applying the formulas for predicting left ventricular pressure were invalid if left ventricular function was abnormal. ${ }^{6}$ Mean Vcf was chosen as the measure of left ventricular function because it was the original measure used by Bennett et al. ${ }^{6}$ Although there may now be better methods of estimating left ventricular function, in the present study mean Vcf $>1 \mathrm{circ} / \mathrm{s}$ was a valuable and fairly strict criterion for good left ventricular function, as was shown by subsequent calculation of ejection fraction from the cineangiograms (by digitising end systolic and end diastolic frames). Thus only one of 29 patients with mean Vcf $>1 \mathrm{circ} / \mathrm{s}$ had an ejection fraction of $<50 \%$, and the mean for the group was $67 \%$. All the patients with a mean Vcf $>1 \mathrm{circ} / \mathrm{s}$ had a normal end systolic dimension on the echocardiogram.

All the echocardiograms were measured regardless of their quality. The technical quality of each echocardiogram was assessed as either good (unquestionably high quality), fair (the sort of quality which would normally be considered acceptable for measurement but which was not quite as clear as the good quality echocardiograms, for example one endocardial boundary poorly defined), or poor. This classification meant that the importance of technical quality in determining the predictive value of echocardiographic measurements could be assessed in the subsequent analysis.

All patients underwent cardiac catheterisation during which peak left ventricular pressure and peak systolic gradient across the aortic valve were measured. These two measurements were correlated with the estimates of left ventricular hypertrophy and predicted left ventricular pressure discussed above. The advantage of using left ventricular pressure as an independent variable is that it circumvents some of the problems associated with coexisting hypertension. Cardiac output was not measured routinely, and although this could have introduced bias in the patients with low cardiac output, part of the subsequent analysis excluded patients with poor left ventricular function (low mean rate of circumferential shortening). None of the patients had important aortic regurgitation on clinical, echocardiographic, or aortographic grounds.

\section{ANALYSIS OF RESULTS}

The ability of the different measures of left ventricular hypertrophy to predict the degree of aortic stenosis (as measured by gradient across the aortic valve or left ventricular pressure) was assessed by calculating sensitivity and specificity, and, in the case of continuous variables, by determining the correlation coefficient as well. To calculate sensitivity and specificity the dividing line between important and non-important aortic stenosis was taken to be a gradient of $50 \mathrm{~mm} \mathrm{Hg}$ or a left ventricular pressure of $180 \mathrm{~mm} \mathrm{Hg}$.

Sensitivity... $(\%)=($ true . positives correctly diagnosed/total true positives) $\times 100$

Specificity. $(\%)=($ true negatives correctly diagnosed/total true negatives) $\times 100$ 
Table 1 Sensitivity and specificity of various measures of left ventricular hypertrophy as predictors either of the gradient across the aortic valve or of left ventricular pressure in patients with aortic stenosis.

\begin{tabular}{|c|c|c|c|c|c|c|}
\hline Predictor & Criterion & Predicted & Sensitivity (\%) & Specificity (\%) & Accuracy (\%) & Group \\
\hline $\begin{array}{l}\text { Clinical LVH } \\
\text { ST depression } \\
\text { Sokolow-Lyon }^{1} \\
\text { MçPhie }^{2} \\
\text { Meand }_{d} \\
\text { Bennett }^{6} \\
\text { Aziz }^{7}\end{array}$ & $\begin{array}{l}\text { Present or absent } \\
\text { ST depression }>1 \mathrm{~mm} \\
S-V 1+R-V 5 / 6 \geqslant 35 \mathrm{mV} \\
\text { Max } S+M a x R \geqslant 45 \mathrm{mV} \\
\operatorname{Mean}_{d} \geqslant 1 \cdot 15 \mathrm{~cm} \\
\mathrm{LVP}_{\mathrm{p}} \geqslant 180 \mathrm{~mm} \mathrm{Hg} \\
\mathrm{LVP}_{\mathrm{p}} \geqslant 180 \mathrm{~mm} \mathrm{Hg}\end{array}$ & $\begin{array}{l}\text { AVG } \\
\text { LVP } \\
\text { AVG } \\
\text { LVP } \\
\text { AVG } \\
\text { LVP } \\
\text { AVG } \\
\text { LVP } \\
\text { AVG } \\
\text { LVP } \\
\text { AVG } \\
\text { LVP } \\
\text { AVG } \\
\text { LVP }\end{array}$ & $\begin{array}{l}81 \\
73 \\
78 \\
83 \\
85 \\
83 \\
74 \\
77 \\
89 \\
77 \\
34 \\
38 \\
33 \\
38\end{array}$ & $\begin{array}{r}54 \\
44 \\
73 \\
61 \\
31 \\
24 \\
57 \\
47 \\
73 \\
81 \\
83 \\
75 \\
100 \\
93\end{array}$ & $\begin{array}{l}68 \\
58 \\
76 \\
75 \\
69 \\
64 \\
69 \\
68 \\
83 \\
79 \\
60 \\
59 \\
56 \\
69\end{array}$ & $\begin{array}{l}1 \\
1 \\
1 \\
1 \\
1 \\
1 \\
1 \\
1 \\
4 \\
4 \\
4 \\
4 \\
4\end{array}$ \\
\hline
\end{tabular}

Mean $_{\mathrm{f}}$, mean diastolic left ventricular wall thickness; LVH, left ventricular hypertrophy; AVG, aortic valve gradient; LVP, left ventricular pressure; $L V P_{p}$, predicted left ventricular pressure. Bennett and Aziz are the two formulas for calculating $L V P$.

Accuracy $(\%)=(($ positives + negatives correctly diagnosed)/total tested) $\times 100$

(reference ${ }^{9}$ )

Correlations between the gradient or left ventricular pressure and the various measures of left ventricular hypertrophy were made initially with all the patients included (group 1), and then with subgroups selected from group 1: group 2, all patients with high quality echocardiograms; group 3, those patients with a mean rate of circumferential shortening $>1 \mathrm{circ} / \mathrm{s}$ (a prerequisite for the application of Bennett's formula ${ }^{6}$; group 4, those patients with high quality echocardiograms and mean rate of circumferential shortening $>1 \mathrm{circ} / \mathrm{s}$; group 5, those patients with fair quality echocardiograms and mean rate of circumferential shortening $>1 \mathrm{circ} / \mathrm{s}$.

Although these groupings could only be expected to affect the correlations of the echo-derived variables, identical groups were used to determine the correlation of electrocardiographic variables with the pressure gradient across the aortic valve and left ventricular pressure to avoid the possibility that selection of patients from the total study population might have created unrepresentative groups. A group of 13 children aged less than 16 years was also analysed separately (group 6).

\section{Results}

\section{CLINICAL ASSESSMENT}

Left ventricular hypertrophy detected clinically had a reasonable sensitivity but poor specificity (Table 1).

PREDICTION OF SEVERITY OF AORTIC STENOSIS BY ELECTROCARDIOGRAM

Table 1 gives the sensitivity and specificity for the

Table 2 Correlation coefficients for relations between measures of left ventricular hypertrophy and the pressure gradient across the aortic valve or left ventricular pressure

\begin{tabular}{|c|c|c|c|c|c|c|c|}
\hline \multirow[b]{2}{*}{ Measure of $L V H$} & \multirow[b]{2}{*}{$A V G$ or $L V P$} & \multicolumn{6}{|l|}{ Group } \\
\hline & & $\begin{array}{l}l \\
(n=119)\end{array}$ & $\begin{array}{l}2 \\
(n=50)\end{array}$ & $\begin{array}{l}3 \\
(n=62)\end{array}$ & $\begin{array}{l}4 \\
(n=29)\end{array}$ & $\begin{array}{l}5 \\
(n=25)\end{array}$ & $\begin{array}{l}6 \\
(n=13)\end{array}$ \\
\hline $\begin{array}{l}\text { S-V1 + R-V5/6 } \\
\text { Max R + Max S } \\
\text { Mean }_{d} \\
\text { Mass } \\
\text { Bennett }^{6} \\
\text { Aziz }^{7}\end{array}$ & $\begin{array}{l}\text { AVG } \\
\text { LVP } \\
\text { AVG } \\
\text { LVP } \\
\text { AVG } \\
\text { LVP } \\
\text { AVG } \\
\text { LVP } \\
\text { AVG } \\
\text { LVP } \\
\text { AVG } \\
\text { LVP }\end{array}$ & $\begin{array}{l}0.27 \\
0.08 \\
0.23 \\
0.12 \\
0.45 \\
0.52 \\
0.36 \\
0.40 \\
0.18 \\
0.16 \\
0.35 \\
0.39\end{array}$ & $\begin{array}{l}0.42 \\
0.14 \\
0.23 \\
0.24 \\
0.63 \\
0.66 \\
0.50 \\
0.54 \\
0.05 \\
0.005 \\
0.58 \\
0.58\end{array}$ & $\begin{array}{r}0.12 \\
-0.10 \\
0.22 \\
0.07 \\
0.43 \\
0.63 \\
0.41 \\
0.58 \\
0.31 \\
0.34 \\
0.33 \\
0.46\end{array}$ & $\begin{array}{l}0.34 \\
0.05 \\
0.12 \\
0.01 \\
0.59 \\
0.75 \\
0.51 \\
0.68 \\
0.39 \\
0.39 \\
0.60 \\
0.68\end{array}$ & $\begin{array}{l}0.34 \\
0.05 \\
0.40 \\
0.22 \\
0.23 \\
0.44 \\
0.29 \\
0.40 \\
0.35 \\
0.35 \\
0.12 \\
0.13\end{array}$ & $\begin{array}{l}0.32 \\
0.42 \\
0.41 \\
0.58 \\
0.37 \\
0.19 \\
- \\
- \\
0.72 \\
0.68 \\
0.48 \\
0.30\end{array}$ \\
\hline
\end{tabular}

Mean $_{\text {, }}$ mean diastolic left ventricular wall thickness; AVG, aortic valve gradient; LVH, left ventricular hypertrophy; LVP, left ventricular pressure. 

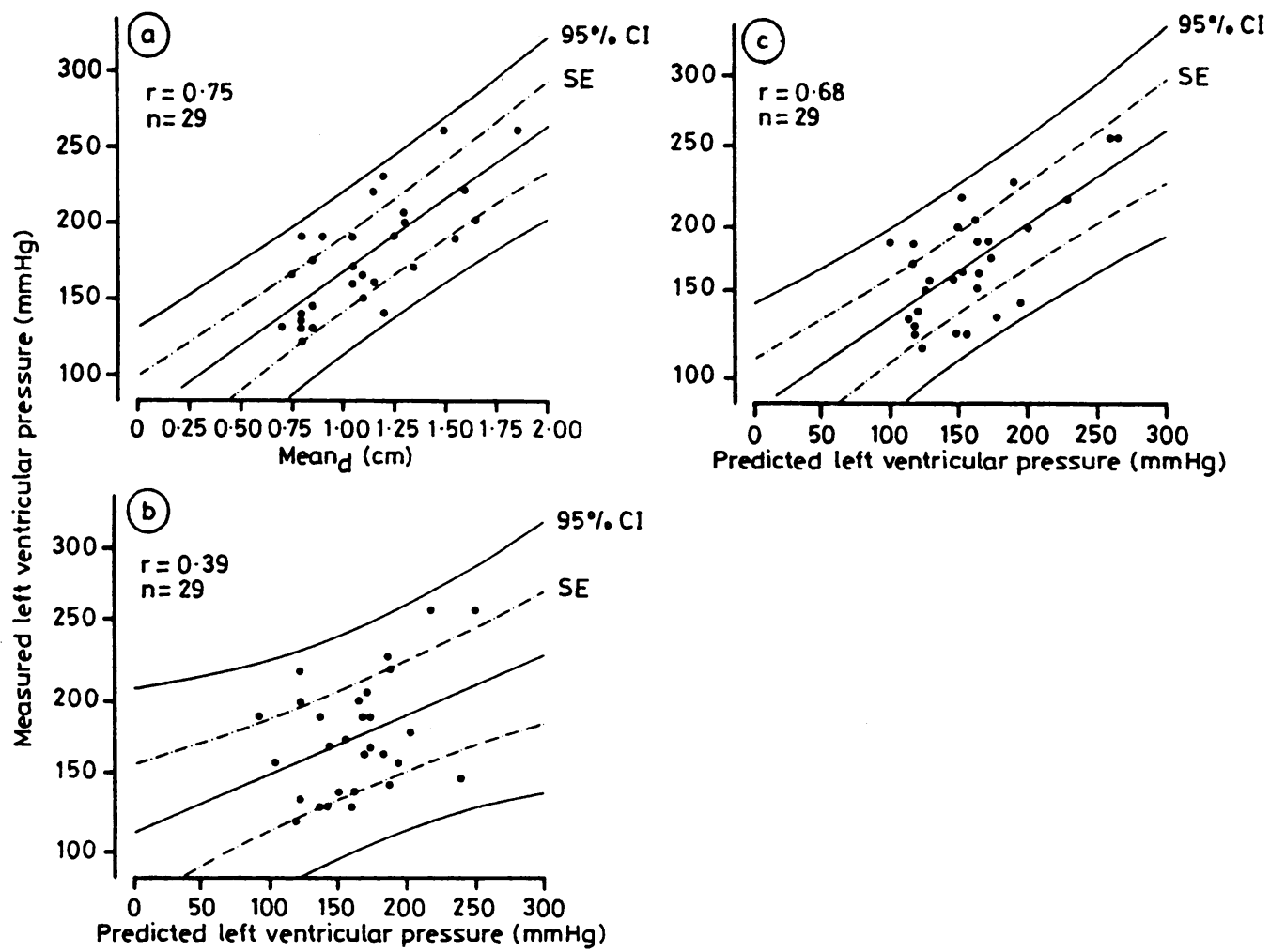

Correlation of measured left ventricular pressure with three variables in 29 patients with high quality echocardiograms and good left ventricular function: (a) mean end diastolic left ventricular wall thickness (mean ${ }_{\mathrm{d}}$ ); (b) predicted left ventricular pressure as calculated from the formula of Bennett et al $^{6}$; and (c) predicted left ventricular pressure as calculated from the formula of Aziz et al..$^{7} 95 \%$ confidence intervals (95\% CI) for standard error (SE) for the prediction of left ventricular pressures measured at catheterisation are shown.

voltage criteria and ST depression. Sensitivity was fair but specificity poor for the voltage criteria. Sensitivity was similar and specificity greater with ST depressions, giving an overall accuracy that was $5-8 \%$ more than by voltage criteria. Correlation coefficients relating precordial voltages to pressure gradient across the aortic valve and left ventricular pressure were low (Table 2).

PREDICTION OF SEVERITY OF AORTIC STENOSIS BY ECHOCARDIOGRAPHY

\section{Left ventricular wall thickness}

Correlations were determined between left ventricular pressure or pressure gradient across the aortic valve and septal thickness, left ventricular posterior wall thickness, and mean left ventricular wall thickness at end systole and end diastole. In general end diastolic measurements correlated better with the haemodynamic variables than end systolic measurements, and mean wall thickness correlated better than either septal or posterior wall thickness alone. In the group as a whole (group 1) left ventricular wall thickness predicted the severity of stenosis better than precordial electrocardiographic voltages. The highest correlation coefficient was found when 29 patients with good quality echocardiograms and mean $\mathrm{Vcf}>1 \mathrm{circ} / \mathrm{s}$ were selected (group 4) and the relation between mean diastolic wall thickness and left ventricular pressure was examined ( $r=0.75$ ) (Table 2, Fig. a).

Sensitivity and specificity were calculated based on the premise that a mean left ventricular wall thickness $>1.15 \mathrm{~cm}$ at end diastole indicated important ventricular hypertrophy (all echocardiographic measurements were made to the nearest 0.1 $\mathrm{cm}$, but the process of calculating means produced figures with two places of decimals). For group 4 this gave a sensitivity of $89 \%$, specificity of $73 \%$, and accuracy of $83 \%$ for the prediction of pressure gradient across the aortic valve, the highest values 
for any of the methods used in this study. When the fair quality echocardiograms of patients with a mean rate of circumferential shortening $>1 \mathrm{circ} / \mathrm{s}$ were analysed separately (group 5) correlations with left ventricular pressure and pressure gradient across the aortic valve were poor and resembled correlations with precordial electrocardiographic voltage. Even with the high quality echocardiograms, $95 \%$ confidence intervals for predicing left ventricular pressure from mean diastolic wall thickness were wide (Fig. a)-with a mean wall thickness of $1.15 \mathrm{~cm}$ predicting a left ventricular pressure of between 130 and $230 \mathrm{~mm}$ Hg. A mean wall thickness of $1.75 \mathrm{~cm}$ or greater was highly likely to be associated with a left ventricular pressure of greater than $180 \mathrm{~mm} \mathrm{Hg}$.

\section{Left ventricular mass}

The pattern of correlation coefficients for left ventricular mass was qualitatively similar to that with wall thickness, but less close (Table 2).

\section{Predicted left ventricular pressure}

Neither of the two formulas for predicting left ventricular pressure was as closely correlated with measured left ventricular pressure as was mean diastolic wall thickness, and $95 \%$ confidence intervals were wider (Table 2, Fig. b). Again, end diastolic measurements (as used in the formula of Aziz) were better predictors than end systolic measurements (as used in the formula of Bennett).

When a group (group 6 ) of children ( $<16$ years) was analysed, the results were completely different (Table 2). The correlation of pressure gradient across the aortic valve or left ventricular pressure with mean diastolic wall thickness was poor, presumably because of the wide range of ages and therefore heart sizes in the group. The formulas for predicting left ventricular pressure, particularly the Bennett formula, were considerably more accurate.

\section{Discussion}

The electrocardiographic ${ }^{9-11}$ and echocardiographic $^{12}$ methods of demonstrating left ventricular hypertrophy have been separately evaluated in several studies, but the strengths and weaknesses of the methods cannot be demonstrated except by comparing them within the same group of patients. In one study in which this has been done it was concluded that precordial voltages were more accurate in predicting the severity of aortic stenosis than was echocardiographic measurement of left ventricular hyertrophy. ${ }^{13}$ The criteria for diagnosing left ventricular hypertrophy by echocardiogram were not stated, however, and the quality of the echocardiograms was not assessed.

One of the strengths of electrocardiography is that it can be performed on all patients and there are no important technical constraints in making a recording. With echocardiography the technical quality of the recording is of great importance, particularly when thicknesses are measured, since even small errors are a considerable proportion of the total measurement. ${ }^{14}$ In this study high standards were achieved in $42 \%$ of patients. When poorer quality echocardiograms were analysed, the correlations with pressure gradient across the aortic valve and left ventricular pressure were reduced to those achieved by electrocardiogram. When high quality echocardiograms were available, mean diastolic left ventricular wall thickness was the best predictor of the severity of aortic stenosis. In children wall thickness was a poor predictor of aortic stenosis because the range of heart sizes was much greater than that in adults. Precordial voltage, however, was if anything more accurate when applied to children than when applied to adults.

\section{HYPERTENSION}

Hypertension is a potentially confounding variable in the relation between left ventricular wall thickness and pressure gradient across the aortic valve. Patients with established hypertension were excluded from the study, and no patients were on hypotensive treatment (even for angina). On admission to hospital five patients had a diastolic blood pressure of $>100 \mathrm{~mm} \mathrm{Hg}$, but none was $>110$ $\mathrm{mm} \mathrm{Hg}$. Their mean (SD) systolic blood pressure was 158 (13) $\mathrm{mm} \mathrm{Hg}$. Because hypertension had not previously been recognised in these patients they were included in the study. Only two satisfied the criteria for group 4 (mean rate of circumferential shortening $>1 \mathrm{circ} / \mathrm{s}$ and high quality echocardiograms).

FORMULAS FOR PREDICTING LEFT

VENTRICULAR PRESSURE

The theoretical basis for predicting left ventricular pressure is a highly simplified form of the law of Laplace, which states that circumferential stress in a thin-walled sphere is proportional to internal pressure and cavity diameter and inversely proportional to wall thickness. With several major assumptions this may be applied to the left ventricle. ${ }^{15}$ On the basis that the hypertrophic response acts to keep peak circumferential wall stress constant in pressure overload (at least until the left ventricle fails ${ }^{16}$ ), left ventricular pressure is proportional to the ratio of left ventricular wall thickness to cavity dimension. Bennett et al were the first to realise the potential of this relation to predict 
left ventricular pressure by non-invasive means. ${ }^{6} \mathrm{~A}$ number of similar formulas have since been devised 17-21 and have been shown to predict left ventricular pressure with some accuracy, although there have been reservations. ${ }^{22}{ }^{23}$ The formula of Aziz et al $^{7}$ was claimed to be superior because it used end diastolic measurements (rather than the end systolic measurements of Bennett's formula), since peak systolic wall stress occurs at the onset of systole before there has been appreciable fibre shortening.

Whatever the theoretical basis for the formulas, they all contain the well documented relation between left ventricular pressure and wall thickness, and for practical purposes it is important to know how much the formulas depends on this relation for their correlation, and how much the inclusion of the second variable, cavity dimension, alters the correlation. In the present study it was quite clear that except in children the correlation between left ventricular pressure and ventricular wall thickness was closer than the correlation between measured and predicted left ventricular pressures from the two formulas whatever group of adult patients was chosen. Left ventricular wall thickness was a poor predictor of left ventricular pressure in children, however, presumably because of the large range of heart sizes, and in children the Bennett formula performed reasonably well $(r=0.68)$. There is a close relation between cavity dimension and body surface area in children, even in those with aortic stenosis, ${ }^{7}$ and the most likely explanation of these findings is that cavity dimension functions as a normalising variable and therefore is of most value in children where the range of cavity dimensions is largest. Although sensitivity was very low for the Aziz formula, specificity was high $(93 \%)$. This was largely due to the fact that the formula tended to underestimate left ventricular pressure, particularly at the lower end of the pressure range as is shown by the regression line (Fig. c).

There are several other possible reasons why the formulas for predicting left ventricular pressure from echocardiographic recordings are inaccurate.

\section{Poor quality of echocardiographic recordings}

Poor images cannot provide accurate measurements, and it is clear that the quality of echocardiographic recording is highly important. Poor image quality does not, however, explain why in the present study left ventricular wall thickness was a better predictor of left ventricular pressure than the two formulas since the same echocardiograms were used for determining both sets of correlations.

Inaccuracies of measurement

Small inaccuracies of measurement are inevitable even in good quality echocardiograms, ${ }^{24}$ although making repeated measurements minimises the errors. ${ }^{14}$ In the calculation of a ratio such as $\mathrm{LVW}_{d} / \mathrm{D}_{\mathrm{d}}$, however, inaccuracies tend to be amplified because an error in locating either endocardial boundary will increase one measurement and decrease the other. An error of as little as $1 \mathrm{~mm}$ in either endocardial boundary may change the predicted left ventricular pressure by as much as $20 \mathrm{~mm} \mathrm{Hg}$.

Assumptions in the derivation of peak circumferential wall stress

The estimation of peak circumferential wall stress by $M$ mode echocardiography requires the assumption that the left ventricle behaves as a thin walled sphere. If this assumption is only partly correct then the accuracy with which left ventricular pressure can be predicted by $M$ mode echocardiography will be limited, even with a technically perfect recording.

\section{Constancy of wall stress in aortic stenosis}

There is now a considerable body of experience suggesting that the process of adaptation to increase afterload is stimulated by abnormal wall stress and completed only when wall stress is returned to normal. ${ }^{1625}$ There have, however, been two reports of abnormal wall stress in patients with compensated aortic stenosis. 2627

The results of this study allow a clearer understanding of the place of these various methods of assessing left ventricular hypertrophy in the investigation of patients suspected of having important aortic stenosis. Of course in the clinical setting none of these variables would be used alone for the assessment of an individual patient, but a knowledge of the sensitivity, specificity, and confidence intervals indicates how much weight to place on a particular result. In adults, who ate good echocardiographic subjects, mean diastolic wall thickness provides more reliable information than either the electrocardiogram or left ventricular pressure predicted from formulas. If the echocardiograms are anything less than high quality their reliability resembles that of the electrocardiogram. In children left ventricular pressure predicted from the echocardiogram is the most accurate method, but the correlations are not sufficiently strong for an investigator to be confident in borderline cases.

I am grateful to Graham Leech for his criticism of this paper.

\section{References}

1 Sokolow M, Lyon TP. The ventricular complex in left 
ventricular hypertrophy as obtained by unipolar precordial and limb leads. Am Heart $\mathcal{F}$ 1948; 37: 161-86.

2 McPhie J. Left ventricular hypertrophy: electrocardiographic diagnosis. Australasian Annals of Medicine 1958; 7: 317-27.

3 Sahn DJ, DeMaria A, Kisslo J, Weyman A. Recommendations regarding quantitation in $\mathrm{M}$-mode echocardiography: results of a survey of echocardiographic measurements. Circulation 1978; 58: 1072-83.

4 Teichholz LE, Kreulen TH, Herman MV, Gorlin R. Problems in echocardiographic volume determinations echoangiographic correlations in the presence or absence of asynergy. Am $\mathcal{f}$ Cardiol 1976; 37: 7-11.

5 Bardeen CR. Determination of the size of the heart by means of X-rays. Am $\mathcal{F}$ Anat 1918; 23: 423-87.

6 Bennett DW, Evans DW, Raj MVJ. Echocardiographic left ventricular dimensions in pressure and volume overload. Their use in assessing aortic stenosis. $\mathrm{Br}$ Heart $\mathcal{f} 1975$; 37: 971-7.

7 Aziz KU, van Grondelle A, Paul MH, Muster AJ. Echocardiographic assessment of the relation between left ventricular wall and cavity dimensions and peak systolic pressure in children with aortic stenosis. $A m \mathcal{F}$ Cardiol 1977; 40: 775-80.

8 Fortuin NJ, Hood WP Jr, Craige E. Evaluation of left ventricular function by echocardiography. Circulation 1972; 46: 26-35.

9 Reichek N, Devereux RB. Left ventricular hypertrophy: relationship of anatomic, echocardiographic and electrocardiographic findings. Circulation 1981; 63: 1391-8.

10 Romhilt DW, Bove KE, Norris RJ, et al. A critical appraisal of the electrocardiographic criteria for the diagnosis of left ventricular hypertrophy. Circulation 1969; 40: 185-95.

11 Clementy J, Bergere P, Bricaud H. Electrocardiography and vectocardiography in the evaluation of left ventricular hypertrophy due to pressure overload. Eur Heart $\mathcal{F}$ 1982; 3 (suppl A): 37-47.

12 Voeklel AG, Kendrick M, Pietro DA, et al. Noninvasive tests to evaluate the severity of aortic stenosis. Chest 1980; 77: 155-60.

13 Nakamura V, Hultgren HN, Shettigar UR, Fowles RE.
Non-invasive evaluation of the severity of aortic stenosis in adult patients. Am Heart $\mathcal{F} 1984$; 107: 959-67.

14 Bullock RE, Amer H, Albers C, et al. Digitisation of M-mode echocardiography. Its reproducibility and sources of imprecision. In: Hunter S, Hall R, eds. Echocardiography 2. Edinburgh and London: Churchill Livingstone, 1984: 15-32.

15 Ford LE. Heart size. Circ Res 1976; 39: 297-303.

16 Grossman W, Jones D, McLaurin LP. Wall stress and patterns of hypertrophy in the human left ventricle. $\mathcal{f}$ Clin Invest 1975; 56: 56-64.

17 Glanz S, Hellenbrand WE, Berman MA, Talner NS. Echocardiographic assessment of the severity of aortic stenosis in children and adolescents. $\mathrm{Am} \mathcal{F}$ Cardiol 1976; 38: 620-5.

18 Schwartz A, Vignola PA, Walker HJ, King ME, Goldblatt A. Echocardiographic estimation of aortic valve gradient in aortic stenosis. Ann Intern Med 1978; 89: 329-35.

19 Blackwood RA, Bloom KR, Williams CM. Aortic stenosis in children. Circulation 1978; 57: 263-8.

20 Gaasch WH. Left ventricular radius to wall thickness ratio. Am f Cardiol 1979; 43: 1189-94.

21 Quinones MA, Mokotoff DM, Nouri S, Winters WL $\mathrm{Jr}$, Miller RR. Non-invasive quantification of left ventricular wall stress. Am $\mathcal{F}$ Cardiol 1980; 45: 782-90.

22 Bass JL, Einzig S, Hong CY, Moller JH. Echocardiographic screening to assess the severity of congenital aortic stenosis in children. Am $\mathcal{F}$ Cardiol 1979; 44: 82-7.

23 Riggs T, Hirschfeld S. Left ventricular pressure in aortic stenosis [Letter]. Am $\mathcal{F}$ Cardiol 1978; $42: 690$.

24 Felner JM, Blumenstein BA, Schlant RC, et al. Sources of variability in echocardiographic measurements. Am f Cardiol 1980; 45: 995-1004.

25 Linzbach AJ. Heart failure from the point of view of quantitative anatomy. Am $\mathcal{f}$ Cardiol 1960; 5: 370-82.

26 Hood WP. Dynamics of hypertrophy in the left ventricular wall of man. In: Alpert NR, eds. Cardiac hypertrophy. New York: Academic Press, 1971: 445-52.

27 Donner R, Carabello BA, Black I, Spann JF. Left ventricular wall stress in compensated aortic stenosis in children. Am $\mathcal{F}$ Cardiol 1983; 51: 946-51. 